\title{
Effect of mir-129 on the Sensitivity Enhancement of Methotrexate and Migration Inhibition in Osteosarcoma Cancer Cells
}

\author{
Junxue $\mathrm{Wu}^{1 \#}$, Chao Zhang ${ }^{1 \#}$, Lin Zheng ${ }^{1}$ and Lu Chen ${ }^{1, *}$ \\ 1 Orthopedics, North Sichuan Medical College Affiliated Hospital, Nanchong, Sichuan, China \\ \# Co-first author \\ * Corresponding author: Lu Chen, North Sichuan Medical College Affiliated Hospital, Nanchong, Sichuan, China. Tel: 008602228332817; \\ Email: luchenvip123@sina.com
}

Received 2020 November 27; Revised 2020 December 28; Accepted 2021 January 15.

\begin{abstract}
Background: MicroRNAs have been recently declared to be contributed to the various aspects of osteosarcoma cells, including growth and survival, apoptosis, invasion, and chemoresistance.

Objectives: The present study aimed to investigate the potentiating effects of miR-129 on the chemosensitivity of Saos-2 osteosarcoma cells to methotrexate (MTX) and underlying mechanisms.

Methods: Saos-2 cells were transfected with miR-129 mimics for $48 \mathrm{~h}$. The cytotoxic effects of miR-129 and MTX on Saos-2 cells were measured using MTT assay. Moreover, a scratch wound healing assay was used to evaluate cell migration, and the apoptosis rate of cancer cells was also measured using ELISA Cell Death Assay and flow cytometry. Eventually, the mRNA expression levels of target genes were measured using quantitative RT-PCR.

Results: The findings of the study revealed that miR-129 mimic transfection significantly increased the expression levels of this miRNA in Saos-2 cells $(\mathrm{P}<0.05)$ and that the combination of MTX with miR-129 transfection led to the enhanced cytotoxic effects of MTX in lower concentrations. miR-129 significantly increased MTX-induced apoptosis levels and decreased the invasive behavior of Saos-2 cells. Eventually, the mRNA expression levels of c-Myc, K-Ras, CXCR4, MMP9, and ADAMTS, as the main genes involved in chemoresistance and cell invasion, were downregulated in miR-129 transfected cells.

Conclusion: The obtained results revealed the important role miR-129 plays in the sensitivity of osteosarcoma cells to MTX and its underlying mechanisms. Therefore, miR-129 might be an appropriate candidate for reversing MTX resistance in osteosarcoma cells.

Keywords: Apoptosis, Chemoresistance, Invasion, miR-129, Osteosarcoma
\end{abstract}

\section{Background}

Osteosarcoma, as highly progressive bone cancer, is considered as one the most prevalent cancer types in humans and its incidence rate is increasing worldwide $(1,2)$. It is ranked among eight top cancers in young adults, adolescents, and teenagers $(3,4)$. The incidence rate of osteosarcoma is higher in males, compared to females (5). Currently, surgery in combination with the chemotherapeutic regime, including methotrexate (MTX) and tomudex has been standardized as the most effective therapeutic strategy for patients with osteosarcoma, such that the five-year survival rates of patients increases up to $65 \%-75 \%$ due to ameliorative effects of therapeutic interventions on symptoms (6). However, similar to other types of human malignancies, there is a low response rate to chemotherapeutic drugs in patients with osteosarcoma, which eventually leads to the recurrence of tumors and clinically unfavorable outcomes (7). The development of resistance against drugs plays a critical role in the failure of therapeutic interventions (8). Therefore, there is an urgent need for deciphering and understanding the exact molecular mechanisms underlying the acquisition of resistance in osteosarcoma (8). Recently, great attention has been paid to the involvement of
microRNAs (miRNAs) in the pathogenesis of osteosarcoma. miRNAs are short-length non-coding RNAs with a critical function in the regulation of gene transcription through binding to the mRNAs and suppression of their translation into functional proteins (9). In addition to the crucial function of miRNAs in cell proliferation, growth, and invasion, it is also demonstrated that miRNAs play an essential role in the development of drug resistance in numerous cancer types $(10,11)$. miR-129 is one the most important tumor suppressor miRNAs, which potentially inhibits the proliferation, survival, and invasion of various cancer cells, as well as cancer cells' resistance to conventional chemotherapeutics $(12,13)$. For instance, miR-129 reverses breast cancer cells' resistance to trastuzumab (11). miR-129 also increases the sensitivity of non-small cell lung cancer cells to chemotherapy (14). Despite the established importance of miR-129 in the various aspects of osteosarcoma pathogenesis, the effects of miR-129 on MTX resistance in osteosarcoma cells and the potential mechanisms have not been elucidated (15-17).

\section{Objectives}

Therefore, this study aimed to investigate the effects of miR-129 transfection on the sensitivity of 
Saos-2 osteosarcoma cells to MTX and underlying mechanisms.

\section{Methods}

\subsection{Cell culture and miRNA transfection}

Saos-2 osteosarcoma cell line was provided from Sun Yat-sen University Cancer Center (Guangzhou, China). Saos-2 cells were cultured in the RPMI-1640 medium containing 10\% fetal bovine serum (FBS; Gibco, Grand Island, NY, USA) and 1\% streptomycin/ penicillin solution. Cells were incubated at $37^{\circ} \mathrm{C}$ in $5 \% \mathrm{CO} 2$, harvested using trypsin-EDTA, and passaged every 2-3 days to maintain exponential growth.

For miRNA transfection, miR-129 mimic (5'GGACTTTCTTCATTCACACCG -3') was designed and obtained from GenePharma Biotech (Shanghai, China). First, Saos- 2 cells were cultured at $5 \times 10^{5}$ cells/well to a six-well plate. Afterward, miR-129 mimic was transfected to cells using Lipofectamine (Invitrogen) in accordance with the manufacturer's guidelines. The final concentration of Lipofectamine used for miR-129 transfection in Saos-2 cells was 50 nM. Cells were also transfected with a control miRNA (5' - TCCGATCGTGAAGCGTTC -3').

\subsection{Evaluating cell proliferation}

The 3-(4, 5-dimethylthiazol-2-yl)-2,5 diphenyltetrazolium bromide (MTT; Bio Basic Co) assay was applied in order to evaluate cell viability following the treatment with MTX, miR-129, and combination of MTX with miR-129. Initially, Saos-2 cells $\left(1 \times 10^{4}\right.$ cells per well) were exposed to different concentrations of MTX (up to $2 \mu \mathrm{M}$ ) and miR-129 (5 $\mu \mathrm{M})$ alone or combination after they were seeded at 96- well plates. Media containing drugs was removed after $24 \mathrm{~h}$ and cells were incubated with MTT solution at $37^{\circ} \mathrm{C}$. Subsequently, the formed formazan crystals were solubilized using dimethyl sulfoxide. The absorbance of each well was examined at $570 \mathrm{~nm}$ with a microplate reader (Bio Tek Instruments, USA).

\subsection{Scratch wound healing assay}

The effects of miR-129 transfection were evaluated on the MTX-mediated suppression of cellular invasion in Saos-2 osteosarcoma cells using a wound-healing assay. For this purpose, cells were seeded into 24-well plates and scraped with pipette tips. Subsequent to washing with Phosphate-buffered saline (PBS), cells were treated with Control miR, miR-129, and afterward were evaluated under phasecontrast microscope 24, 48, and $72 \mathrm{~h}$ post-injury. Migrated cells were measured and quantified using Image J software.

\subsection{ELISA cell death assay}

The ELISA cell death assay, measuring released mono- and oligonucleosomes during apoptosis, was applied to measure apoptosis levels in Saos-2 cells. Briefly, cells were cultured in twelve-well microplates and exposed to MTX, miR-129, and the combination of the two. Cells were harvested and the supernatant was collected after 24 hours of incubations at $37{ }^{\circ} \mathrm{C}$. Afterward, cell death was evaluated using a commercial ELISA kit, according to the manufacturer's protocol.

\subsection{Annexin-V/PI flow cytometry}

Flow cytometric analysis of apoptosis was performed to determine the effect of MTX, miR-129, and their combination on Saos-2 cells. After treatment, cells were harvested, washed twice with cold PBS, resuspended in $500 \mu$ l of binding buffer, and $5 \mu \mathrm{l}$ of annexin V-FITC and $5 \mu \mathrm{l}$ of propidium iodide were added. After incubation for $15 \mathrm{~min}$ at room temperature in the dark, the cells were analyzed using a flow cytometer.

\subsection{RNA isolation and real-time polymerase chain reaction $(P C R)$}

Total RNA was isolated from the ovaries via Trizol reagent (Invitrogen, USA) based on the manufacturer's guidelines. Afterward, complementary DNA templates (cDNA) were synthesized using a cDNA synthesis kit (Bioneer, Korea). Finally, synthesized cDNA was subjected to quantitative real-time PCR (qRT-PCR) in duplicate using SYBR Green master mix and Mic qPCR cycler. GAPDH was used as the reference gene for all samples to normalize the mRNA expression level. The results of qRT-PCR were calculated using the $2^{-\Delta \Delta C T}$ method. Sequences of primers used for amplification of rat miR-129, K-Ras, c-Myc, CXCR-4, MMP9, ADAMTS, and GAPDH have been presented in table 1.

\begin{tabular}{|c|c|c|}
\hline \multirow{2}{*}{ Target gene } & \multicolumn{2}{|c|}{ Sequences $\left(5^{\prime}-3^{\prime}\right)$} \\
\hline & Sense & Anti-sense \\
\hline miR-129 & GGACTTTCTTCATTCACACCG & GACCACTGAGGTTAGAGCCA \\
\hline CXCR-4 & TCTTCСТGСССАССАТСТАСТС & TGCAGCCTGTACTTGTCCGTC \\
\hline K-Ras & GTAGTTGGAGCTGGTGGC & TTTCACACAGCCAGGAG \\
\hline c-Myc & AGGCTCTCCTTGCAGCTGCT & AAGTTCTCCTCCTCGTCGCA \\
\hline MMP9 & TCACAAATCCTCCCCAAGTGG & GAATGCGCCCTAAATCACTGA \\
\hline ADAMTS & ССТCAGCССТTCTGAAAACTTTGCC & GGCACCAAGTCCTCCACACCC \\
\hline Control miR & TCCGATCGTGAAGCGTTC & GTGCAGGGTCCGAGGT \\
\hline GAPDH & GCACCGTCAAGGCTGAGAAC & TGGTGAAGACGCCAGTGGA \\
\hline
\end{tabular}




\subsection{Statistical analysis}

The data were analyzed in GraphPad Prism software (version 6) through the KolmogorovSmirnov test (for the evaluation of the normality of the data in groups), one-way analysis of variance (ANOVA), and Tukey's test. Moreover, the data were presented as mean $\pm \mathrm{SD}$, and a p-value less than 0.05 was considered statistically significant

\section{Results}

\subsection{The effects of miR-129 mimic transfection on the expression levels of miR-129}

The efficacy of miR-129 mimic transfection into Saos-2 cells was evaluated by measuring gene expression levels of miR-129 using qRT-PCR. The qRTPCR was applied $48 \mathrm{~h}$ after transfection and the results showed that the expression levels of miR-129 were significantly higher in transfected cells, compared to the controls $(\mathrm{P}<0.05$; Figure $5 \mathrm{~A})$. Therefore, miR-129 mimic transfection was successful and could increase the expression levels of this miRNA in Saos-2 cells. In addition, transfection with control miR did not exert any significant effect on the expression levels of miR129 ( $\mathrm{P}>0.05$; Figure 5A).

\section{2. miR-129 transfection increased the cytotoxic effect of MTX in Saos-2 cells}

MTT assay was applied to investigate the potentiating impact of miR-129 on the MTX-mediated suppression of cellular proliferation. For this purpose, Saos- 2 cells were treated with $5 \mu \mathrm{M}$ miR-129 or $5 \mu \mathrm{M}$ Control miR for 24, 48, and $72 \mathrm{~h}$. As shown in Figure 1A, miR-129 mimic resulted in the time-dependent suppression in the cellular proliferation. The most potent effect was observed $72 \mathrm{~h}$ after miR-129 transfection. Control miR and reagent used for transfection of miRNAs did not change the proliferation rate of cells, as compared to controls. In addition to miR-129 mimic, cells were treated with various concentrations of MTX $(0-2 \mu \mathrm{M})$ as well. MTX affected cell proliferation of Saos- 2 cells in a dosedependent manner, such that the treatment of cells with 0-0.2 $\mu \mathrm{M}$ dose of MTX did not exert significant cytotoxic effects; however, concentrations more than $0.2 \mu \mathrm{M}$ resulted in the significant inhibition in cells proliferation rate $(\mathrm{P}<0.05$; Figure $1 \mathrm{~B})$. The IC50 value for MTX was $0.61 \mu \mathrm{M}$ for Saos- 2 cells. In addition, the treatment of Saos-2 cells with various concentrations of MTX and $5 \mu \mathrm{M}$ miR-129 led to significant suppression in the proliferation of Saos-2 cells (Figure 1C). The IC50 value for MTX, when combined with miR-129 decreased to $0.12 \mu \mathrm{M}$. Therefore, miR129 led to enhanced cytotoxic effects of MTX in lower concentrations in combination with miR-129.

\section{3. miR-192 transfection potentiated the MTX-} mediated apoptosis in Saos-2 cells

In order to establish the anticancer effects of miR-
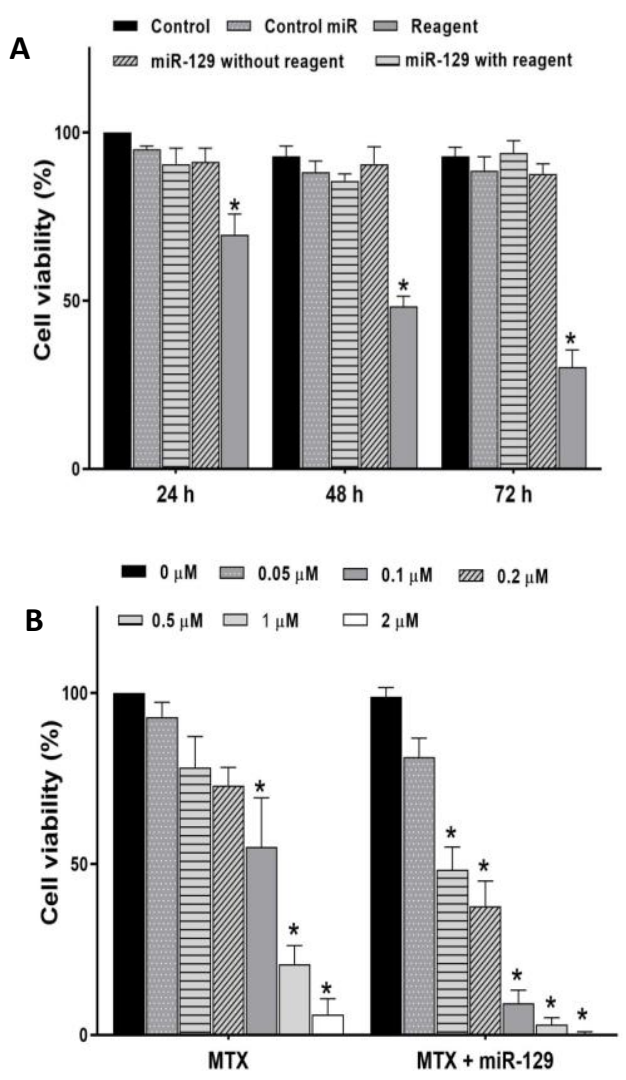

Figure 1. miR-129 enhanced the sensitivity to MTX in Saos-2 Cells. A) $48 \mathrm{~h}$ after transfection with miR-129; B) Transfection with miR-129 and different concentrations of MTX for $24 \mathrm{~h}$. The cell viability was determined using an MTT assay. The results were shown as mean $\pm \mathrm{SD}(\mathrm{n}=4)$; *: $\mathrm{P}<0.05$ versus controls.

129 transfection in Saos- 2 cells and approve results from MTT assay, apoptosis status was evaluated using annexin-V/PI flow cytometry and ELISA cell death assay. Results from the ELISA assay demonstrated that MTX and miR-129 monotreatments in Saos-2 cells led to the significant promotion of apoptosis $(\mathrm{P}<0.05$; Figure 2). A similar finding was found in flow cytometry results. Both interventions significantly increased apoptotic cells number $(\mathrm{P}<0.05$; Figure 3). More importantly, combination of MTX with miR-129 mimic resulted in stronger apoptosis inducing effect $(\mathrm{P}<0.05)$. Therefore, miR-219 was effective in increasing MTXmediated apoptosis in Saos-2 cells.

\section{4. miR-192 transfection suppressed the cellular invasion in Saos-2 cells}

The invasive behavior of Saos-2 cells was evaluated using wound healing assay following miR-129 transfection. The cellular invasion was significantly attenuated in cells transfected with miR129 mimic after 72 h $(\mathrm{P}<0.05$; Figure 4). Therefore, miR-129 had efficacy in suppressing the invasion 


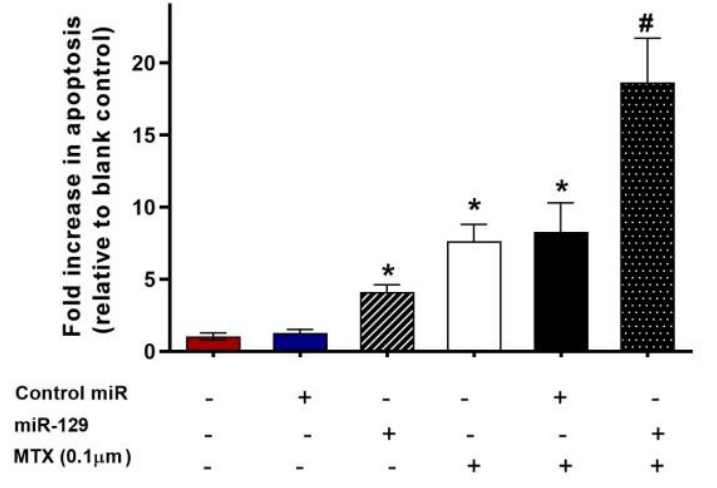

Figure 2. The effect of miR-129 transfection on MTX-induced apoptosis. The Saos-2 cells were treated with mir-129 and MTX $(0.1 \mu \mathrm{M})$, alone or in combination for $48 \mathrm{~h}$. The apoptosis was evaluated using an ELISA cell death kit assay. The data are represented as mean $\pm S D(n=4)$

*: $\mathrm{P}<0.05$ relative blank control or control miR; \#: $\mathrm{P}<0.05$ versus MTX. of Saos- 2 cells.

4.5. miR-192 transfection downregulated the expression levels of CXCR4, c-Myc, K-Ras, MMP9, and ADAMTS in Saos-2 cells

The means of c-Myc, K-Ras, CXCR4, MMP9, and ADAMTS mRNA expression were compared in the control, Control miR, and miR-129 mimic transfected groups. As shown in Figure 5, miR-129 transfection led to a significant drop in the expression levels of CXCR4, c-Myc, K-Ras, MMP9, and ADAMTS in the Saos- 2 cells compared to the control $(\mathrm{P}<0.05)$. Therefore, mRNAs expression levels of target genes were markedly downregulated in transfected cells, indicating the crucial functions of these genes in the progression of osteosarcoma cells. Importantly, data from the control miR treated group were similar in the relative expression of all genes in the Saos-2 cells.
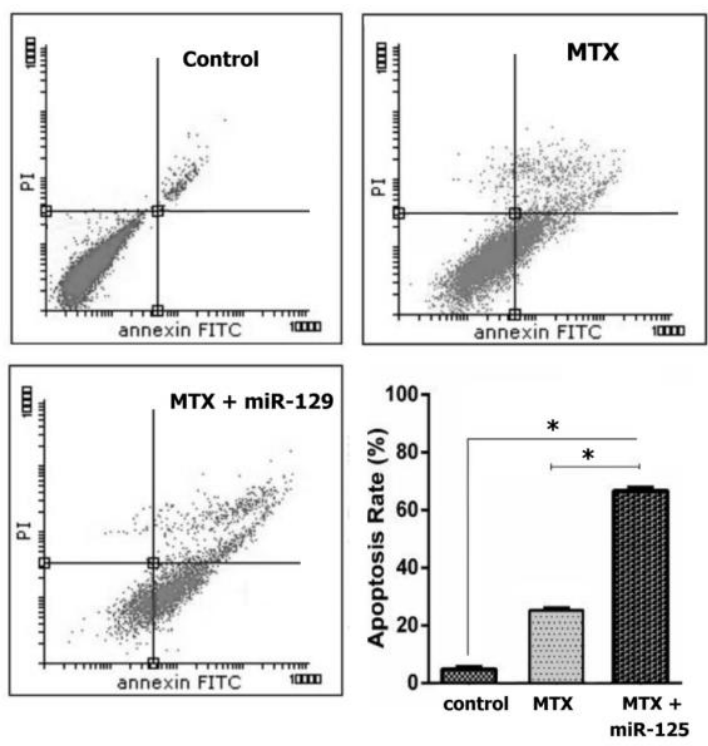

Figure 3. miR-129 transfection effect on Saos-2 cells promotes apoptosis. Annexin-V/PI apoptosis analyzed on cells. The data are represented as mean $\pm S D(n=3) *: P<0.05$.

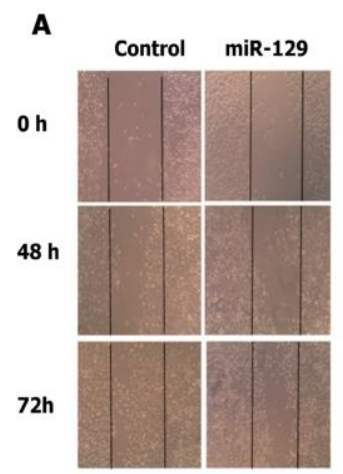

B

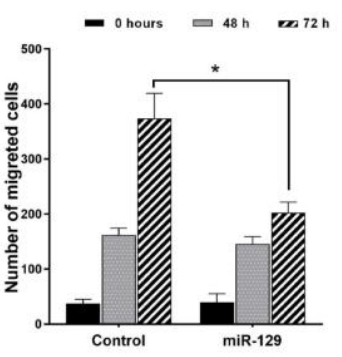

Figure 4. miR-129 reduced Saos-2 cells migration. Wound scratch assay (A) and the numbers of migrated cells in the scratched areas at 0 and $48 \mathrm{~h}$ after miR-129 transfection (B). The data are stated as mean $\pm \mathrm{SD}(\mathrm{n}=3),{ }^{*}: \mathrm{P}<0.05$. 

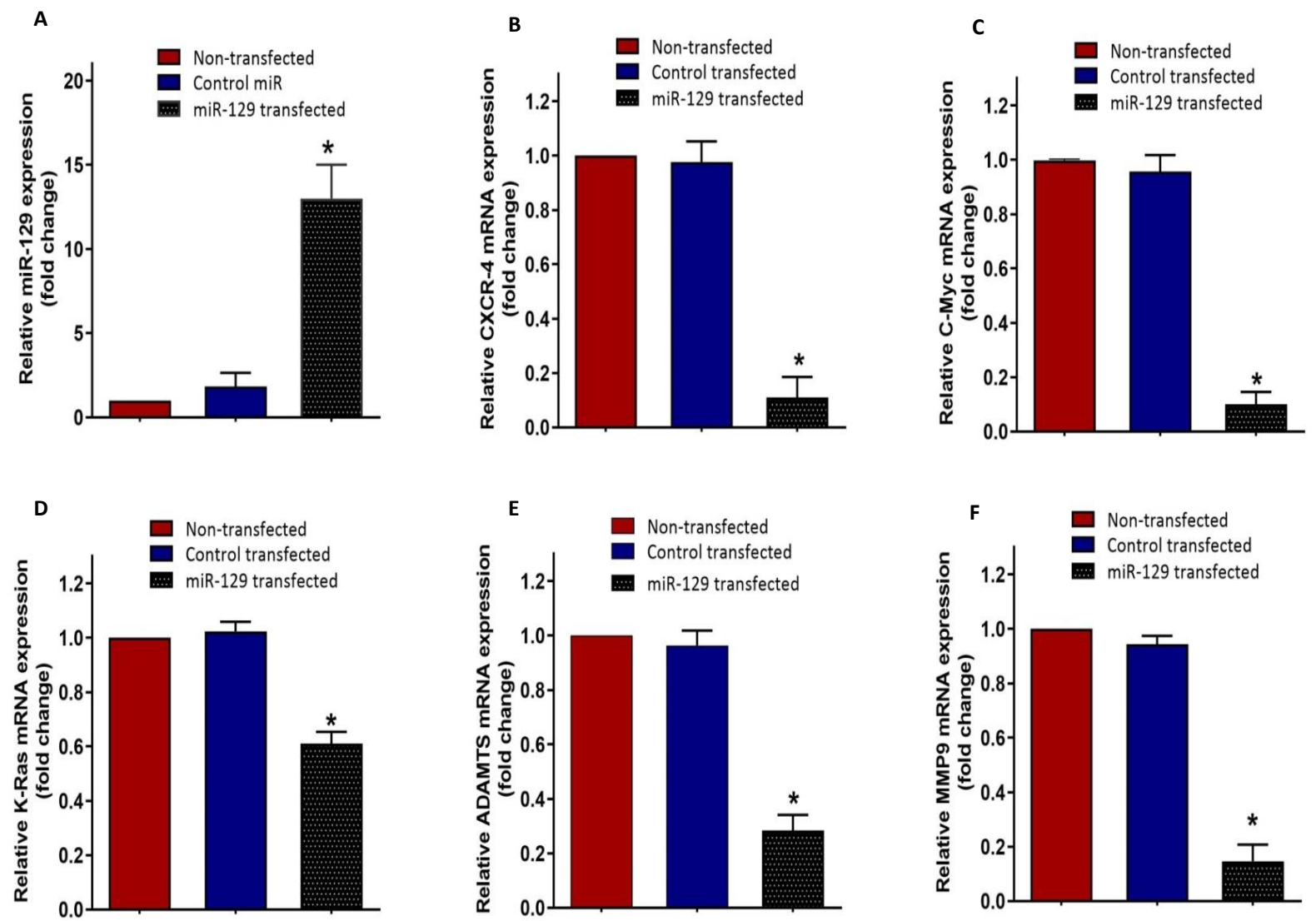

Figure 5. The expression levels of miR-129 (A), CXCR-4 (B), c-Myc (C), K-Ras (D), ADAMTS (E), and MMP9 (F) in Saos-2 cells after $48 \mathrm{~h}$ of transfection. The data are presented as mean $\pm \mathrm{SD}(\mathrm{n}=5)$

$*: \mathrm{P}<0.05$ versus non-transfected and control miR.

\section{Discussion}

An accumulating number of recent studies have demonstrated the critical effects of miR-219 on various aspects of osteosarcoma, such as cell growth and survival, apoptosis, cell invasion, and metastasis $(15,17,18)$. The results of the present study for the first time revealed the great importance of the miRNA in increasing MTX mediated anticancer effects which lead to the reversing of MTX resistance in Saos- 2 cells. Osteosarcoma is one the most challenging human malignancies with high adverse effects on skeletal growth rate in patients (19). Similar to other cancer types, chemotherapy is one the most effective therapeutic strategies in combating osteosarcoma (20). However, the development of multidrug resistance is still a big burden against the complete treatment of osteosarcoma; therefore, decreases the efficacy of chemotherapeutic agents such as MTX (20). An increasing number of previous studies have paid great attention to developing novel strategies with high efficacy in order to overcome multidrug resistance in osteosarcoma. Regarding the importance of miRNAs in osteosarcoma pathogenesis, it is suggested that these tiny RNA molecules are an appropriate candidate in reversing drug resistance and increasing the therapeutic potential of chemotherapeutic agents (21). miR-129 is a tumor suppressor miRNA in osteosarcoma, which is commonly reported to be downregulated in osteosarcoma. Its downregulated profile of expression is also reported in bladder cancer cells resistant to gemcitabine (22); ovarian cancer cells resistant to paclitaxel (23); breast cancer cells resistant to Adriamycin, epirubicin, and docetaxel (24-26); and colorectal cancer cells to oxaliplatin (27). The results of a study conducted by Zeng et al. showed that breast cancer cells transfected with miR-129-5p mimic resulted in the significant inhibition of cellular proliferation and increase in apoptosis which in turn leads to the suppression of adriamycin resistance (28). In the same line, a study performed by Cao et al. revealed that miR-129 overexpression combat cisplatin resistance in gastric cancer cells (29). Similarly, the results of the present study demonstrated significant downregulation of miR-129 in the Saos-2 osteosarcoma cells. Upregulation of this miRNA in Saos- 2 cells revealed the inhibitory effect of MTX on cell proliferation and significantly increased 
its potentiating impact on apoptosis. Therefore, miR129 was effective in reversing MTX resistance in Saos- 2 cells. These findings suggested the pivotal role of miR-192 in increasing MTX-induced apoptosis in Saos- 2 cells.

Moreover, the mRNA expression levels of K-Ras, cMyc, CXCR-4, MMP9, and ADAMTS were measured in cells transfected by miR-129 mimic to elucidate miR129 function in the MTX resistance in Saos-2 cells. Overexpression in K-Ras, c-Myc, CXCR4 (CXCChemokine Receptor-4), and ADAMTS (a disintegrinlike and metalloproteinase domain with thrombospondin type 1 motifs) is reported to be involved in the tumor invasion and metastasis of various cancer types, such as osteosarcoma (30-33). In addition, some miRNAs like miR-224 are reported to modulate drug resistance by targeting $\mathrm{K}$-Ras and increasing c-Myc activity in cancer cells (34). miR-192 reverse chemoresistance to MTX by targeting and suppressing the expression levels of CXCR4 and ADAMTS in MG-63 osteosarcoma cancer cells (3). In addition, MMP-9 is one of the most important MMPs involved in the angiogenesis, migration, invasion, chemo-resistant, and metastasis of cancer cells. Various miRNAs are reported to regulate drug resistance by targeting MMP-9. miR-211 targets MMP-9 in glioma cells to modulate apoptosis and chemosensitivity (35). In this study, it was found that the upregulation of miR-129 led to a decrease in the expression levels of K-Ras, c-Myc, CXCR-4, MMP9, and ADAMTS, as well as the significant reduction in the invasive phenotype of cancer cells. Eventually, the results demonstrated that miR-129 could reduce the expression levels of these genes, which play a critical role in epithelial-mesenchymal transition and cell migration by sensitizing cancer cells to MTX in Saos- 2 cells.

\section{Conclusion}

The present study revealed the importance of miR-129 in osteosarcoma cells' sensitivity to MTX, as a common chemotherapeutic agent used for the treatment of osteosarcoma. The results showed that miR-12 overexpression in osteosarcoma cells in combination with MTX led to a significant downregulation of K-Ras, c-Myc, CXCR-4, MMP9, and ADAMTS along with the induction of apoptosis in cancer cells. Therefore, miR-129 may have a great potential in elevating the sensitivity of MG-63 cells to MTX.

\section{Acknowledgments}

We thank our colleagues in Orthopaedic Surgery Department , North Sichuan Medical College Affiliated Hospital, whose insight and expertise greatly assisted the research.

\section{Footnotes}

Authors' Contribution: J.W and C.Z: Performed experiments and co-wrote the paper.

L.C: Analyzed data and supervised the research.

Conflict of Interests: The authors confirm that there is no conflict of interest regarding the publication of this study.

Ethical Approval: This study was approved by the Ethical Committee of North Sichuan Medical College Affiliated Hospital, Sichuan, China.

Informed consent: Informed consent was not necessary for this in vitro study.

\section{References}

1. Ji Q, Xu X, Song Q, Xu Y, Tai Y, Goodman SB, et al. miR-223-3p inhibits human osteosarcoma metastasis and progression by directly targeting CDH6. Mol Ther. 2018;26(5):1299-312. doi: 10.1016/j.ymthe.2018.03.009. [PubMed: 29628305].

2. Zhu KP, Zhang CL, Ma XL, Hu JP, Cai T, Zhang L. Analyzing the interactions of mRNAs and ncRNAs to predict competing endogenous RNA networks in osteosarcoma chemo-resistance. Mol Ther. 2019;27(3):518-30. doi: 10.1016/j.ymthe.2019.01.001. [PubMed: 30692017].

3. Bazavar M, Fazli J, Valizadeh A, Ma B, Mohammadi E, Asemi Z, et al. miR-192 enhances sensitivity of methotrexate drug to MG-63 osteosarcoma cancer cells. Pathol Res Pract. 2020; 216(11):153176. doi: 10.1016/j.prp.2020.153176. [PubMed: 32861171].

4. Gelberg KH, Fitzgerald EF, Hwang S, Dubrow R. Growth and development and other risk factors for osteosarcoma in children and young adults. Int J Epidemiol. 1997;26(2):272-8. doi: 10.1093/ije/26.2.272. [PubMed: 9169161].

5. Xie X, Li YS, Xiao WF, Deng ZH, He HB, Liu Q, et al. MicroRNA379 inhibits the proliferation, migration and invasion of human osteosarcoma cells by targetting EIF4G2. Biosci Rep. 2017;37(3):BSR20160542. doi: 10.1042/BSR20160542. [PubMed: 28381518].

6. Marina N, Gebhardt M, Teot L, Gorlick R. Biology and therapeutic advances for pediatric osteosarcoma. Oncologist. 2004;9(4):42241. doi: 10.1634/theoncologist.9-4-422. [PubMed: 15266096].

7. Fanelli M, Maria Hattinger C, Vella S, Tavanti E, Michelacci F, Gudeman B, et al. Targeting ABCB1 and ABCC1 with their specific

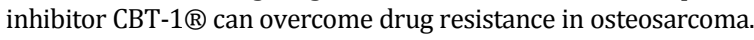
Curr Cancer Drug Targets. 2016;16(3):261-74. doi: 10.2174/ 1568009616666151106120434. [PubMed: 26548759].

8. Duan Z, Gao Y, Shen J, Choy E, Cote G, Harmon D, et al. miR-15b modulates multidrug resistance in human osteosarcoma in vitro and in vivo. Mol Oncol. 2017;11(2):151-66. doi: 10.1002/1878-0261.12015. [PubMed: 28145098].

9. Chen R, Wang G, Zheng Y, Hua Y, Cai Z. Drug resistance-related microRNAs in osteosarcoma: Translating basic evidence into therapeutic strategies. J Cell Mol Med. 2019;23(4):2280-92. doi: 10.1111/jcmm.14064. [PubMed: 30724027].

10. Chen D, Liu D, Chen Z. Potential therapeutic implications of miRNAs in osteosarcoma chemotherapy. Tumor Biol. 2017; 39(9):1010428317705762. doi: 10.1177/1010428317705762. [PubMed: 28933259].

11. Wang JY, Yang Y, Ma Y, Wang F, Xue A, Zhu J, et al. Potential regulatory role of IncRNA-miRNA-mRNA axis in osteosarcoma. Biomed Pharmacother. 2020;121:109627. doi: 10.1016/j. biopha.2019.109627. [PubMed: 31810120].

12. Liang W, Gao B, Fu P, Xu S, Qian Y, Fu Q. The miRNAs in the pathgenesis of osteosarcoma. Front Biosci (Landmark Ed). 2013;18:788-94. doi: 10.2741/4142. [PubMed: 23276964].

13. Salehi M, Sharifi M. Exosomal miRNAs as novel cancer biomarkers: challenges and opportunities. J Cell Physiol. 2018;233(9):6370-80. doi: 10.1002/jcp.26481. [PubMed: 29323722]. 
14. Ma Z, Cai H, Zhang Y, Chang L, Cui Y. MiR-129-5p inhibits nonsmall cell lung cancer cell stemness and chemoresistance through targeting DLK1. Biochem Biophys Res Commun. 2017; 490(2):309-16. doi: 10.1016/j.bbrc.2017.06.041. [PubMed: 28619508].

15. Liu K, Huang J, Ni J, Song D, Ding M, Wang J, et al. MALAT1 promotes osteosarcoma development by regulation of HMGB1 via miR-142-3p and miR-129-5p. Cell Cycle. 2017;16(6): 578-87. doi: 10.1080/15384101.2017.1288324. [PubMed: 28346809].

16. Zhang RM, Tang T, Yu HM, Yao XD. LncRNA DLX6-AS1/miR129-5p/DLK1 axis aggravates stemness of osteosarcoma through Wnt signaling. Biochem Biophys Res Commun. 2018; 507(1-4):260-6. doi: 10.1016/j.bbrc.2018.11.019. [PubMed: 30442366].

17. Han C, Wang W. MicroRNA-129-5p suppresses cell proliferation, migration and invasion via targeting ROCK1 in osteosarcoma. Mol Med Rep. 2018;17(3):4777-84. doi: 10.3892/mmr.2018.8374. [PubMed: 29328417].

18. Long XH, Zhou YF, Peng AF, Zhang ZH, Chen XY, Chen WZ, et al. Demethylation-mediated miR-129-5p up-regulation inhibits malignant phenotype of osteogenic osteosarcoma by targeting Homo sapiens valosin-containing protein (VCP). Tumor Biol. 2015;36(5):3799-806. doi: 10.1007/s13277-014-3021-7. [PubMed: 25566966].

19. Lindsey BA, Markel JE, Kleinerman ES. Osteosarcoma overview. Rheumatol Ther. 2017;4(1):25-43. doi: 10.1007/s40744-0160050-2. [PubMed: 27933467].

20. Misaghi A, Goldin A, Awad M, Kulidjian AA. Osteosarcoma: a comprehensive review. Sicot J. 2018;4:12. doi: 10.1051/sicotj/ 2017028. [PubMed: 29629690].

21. Bach DH, Hong JY, Park HJ, Lee SK. The role of exosomes and miRNAs in drug-resistance of cancer cells. Int J Cancer. 2017; 141(2):220-30. doi: 10.1002/ijc.30669. [PubMed: 28240776].

22. Cao J, Wang Q, Wu G, Li S, Wang Q. miR-129-5p inhibits gemcitabine resistance and promotes cell apoptosis of bladder cancer cells by targeting Wnt5a. Int Urol Nephrol. 2018; 50(10):1811-9. doi: 10.1007/s11255-018-1959-x. [PubMed: 30117016].

23. Wang J, Ye C, Liu J, Hu Y. UCA1 confers paclitaxel resistance to ovarian cancer through miR-129/ABCB1 axis. Biochem Biophys Res Commun. 2018;501(4):1034-40. doi: 10.1016/j.bbrc. 2018.05.104. [PubMed: 29777711].

24. Luan Q, Zhang B, Li X, Guo M. MiR-129-5p is downregulated in breast cancer cells partly due to promoter $\mathrm{H} 3 \mathrm{~K} 27 \mathrm{~m} 3$ modification and regulates epithelial-mesenchymal transition and multi-drug resistance. Eur Rev Med Pharmacol Sci. 2016;20(20):4257-65. [PubMed: 27831649].

25. Yao N, Fu Y, Chen L, Liu Z, He J, Zhu Y, et al. Long non-coding RNA NONHSAT101069 promotes epirubicin resistance, migration, and invasion of breast cancer cells through NONHSAT101069/miR-129-5p/Twist1 axis. Oncogene. 2019; 38(47):7216-33. doi: 10.1038/s41388-019-0904-5. [PubMed: 31444414].

26. Zhang Y, Wang Y, Wei Y, Li M, Yu S, Ye M, et al. MiR-129-3p promotes docetaxel resistance of breast cancer cells via CP110 inhibition. Sci Rep. 2015;5:15424. doi: 10.1038/srep15424. [PubMed: 26487539].

27. Ghanbarian M, Afgar A, Yadegarazari R, Najafi R, TeimooriToolabi L. Through oxaliplatin resistance induction in colorectal cancer cells, increasing ABCB1 level accompanies decreasing level of miR-302c-5p, miR-3664-5p and miR-129-5p. Biomed Pharmacother. 2018;108:1070-80. doi: 10.1016/j.biopha.2018.09.112. [PubMed: 30372807].

28. Zeng H, Wang L, Wang J, Chen T, Li H, Zhang K, et al. microRNA129-5p suppresses Adriamycin resistance in breast cancer by targeting SOX2. Arch Biochem Biophys. 2018;651:52-60. doi: 10.1016/j.abb.2018.05.018. [PubMed: 29802821]

29. Cao H, Xiao C, Lu H, Yu H, Hong H, Guo C, et al. MiR-129 reduces CDDP resistance in gastric cancer cells by inhibiting MAPK3. Eur Rev Med Pharmacol Sci. 2019;23(15):6478-85. doi: 10.26355/eurrev_201908_18531. [PubMed: 31378887].

30. Lou L, Tian M, Chang J, Li F, Zhang G. MiRNA-192-5p attenuates airway remodeling and autophagy in asthma by targeting MMP-16 and ATG7. Biomed Pharmacother. 2020;122:109692. doi: 10.1016/j.biopha.2019.109692. [PubMed: 31918268].

31. Han G, Wang Y, Bi W. c-Myc overexpression promotes osteosarcoma cell invasion via activation of MEK-ERK pathway. Oncol Res. 2012;20(4):149-56. doi: 10.3727/096504012x135222 27232237. [PubMed: 23461061].

32. Alper M, Kockar F. IL-6 upregulates a disintegrin and metalloproteinase with thrombospondin motifs 2 (ADAMTS-2) in human osteosarcoma cells mediated by JNK pathway. Mol Cell Biochem. 2014;393(1-2):165-75. doi: 10.1007/s11010014-2056-9. [PubMed: 24752352].

33. Zhang H, He QY, Wang GC, Tong DK, Wang RK, Ding WB, et al. miR-422a inhibits osteosarcoma proliferation by targeting BCL2L2 and KRAS. Biosci Rep. 2018;38(2):BSR20170339. doi: 10.1042/BSR20170339. [PubMed: 29358307].

34. Amankwatia E, Chakravarty P, Carey F, Weidlich S, Steele R Munro A, et al. MicroRNA-224 is associated with colorectal cancer progression and response to 5-fluorouracil-based chemotherapy by KRAS-dependent and-independent mechanisms. $\mathrm{Br} J$ Cancer. 2015;112(9):1480-90. doi: 10.1038/bjc.2015.125. [PubMed: 25919696].

35. Asuthkar S, Velpula KK, Chetty C, Gorantla B, Rao JS. Epigenetic regulation of miRNA-211 by MMP-9 governs glioma cell apoptosis, chemosensitivity and radiosensitivity. Oncotarget. 2012;3(11):1439-54. doi: 10.18632/oncotarget.683. [PubMed: 23183822]. 